\title{
Análise de modos de pensar o conceito de Substância Mobilizadas por professores de Ciências
}

\author{
Analysis of ways thinking the concept of Substance Mobilized by Science \\ Analisis de las formas de pensar sobre el concepto de Sustancia Movilizadas por los profesores de
} Ciencias

Recebido: 07/07/2021 | Revisado: 16/07/2021 | Aceito: 30/07/2021 | Publicado: 05/08/2021

\author{
Geany de Sousa Lima \\ ORCID: https://orcid.org/0000-0001-7422-7222 \\ Universidade Federal do Vale do São Francisco, Brasil \\ E-mail: geanylima_@hotmail.com \\ Kassielly Raimunda Dias da Silva \\ ORCID: https://orcid.org/0000-0002-7964-8226 \\ Universidade Federal Rural de Pernambuco, Brasil \\ E-mail: kassiellydias@hotmail.com \\ Antônio Inácio Diniz Júnior \\ ORCID: https://orcid.org/0000-0002-2207-9376 \\ Universidade Federal Rural de Pernambuco, Brasil \\ E-mail: antonioinaciodj@gmail.com
}

\begin{abstract}
Resumo
Este artigo teve por objetivo analisar modos de pensar do conceito de substância mobilizadas na fala de dois professores de Ciências do $9^{\circ}$ ano do Ensino Fundamental de duas escolas da rede pública de São Raimundo NonatoPI. Para tanto, nos guiamos na teoria dos perfis conceituais que discutem acerca da pluralidade de significados que um determinado conceito científico pode apresentar, mais especificamente o conceito de substância, uma vez que seu entendimento é muito importante para a aprendizagem dos estudantes e na compreensão de outros conceitos químicos. Essa pesquisa foi realizada em duas etapas, na primeira etapa foi aplicado um questionário para traçar o perfil profissional dos docentes e mapear as principais concepções empregadas para o conceito em tela. A segunda etapa correspondeu à observação de três aulas sobre o conceito de substância e suas aplicações ministradas pelos os sujeitos em investigação, que foram registradas com o auxílio de equipamentos audiovisuais. Assim, os resultados apontaram uma polissemia de conceitos sobre substância, emergindo nas falas dos dois professores investigados e, assim, constatamos que eles utilizam em suas respostas várias formas de pensar esse conceito, seja uma linguagem mais formal, a científica, ou uma maneira de pensar mais simples, a linguagem cotidiana. Com isso, percebemos que nem sempre na escola são empregados conceitos aceitos cientificamente para se apresentar aos alunos um determinado termo científico, como é o caso de substância química, mas vale ressaltar que toda forma de pensamento deve ser considerada, porquanto contribuem para a construção de novas formas de significados.
\end{abstract}

Palavras-chave: Perfil conceitual; Substância; Professores; Ensino de Ciências.

\begin{abstract}
This article aimed to analyze ways of thinking about the concept of substance mobilized in the speech of two science teachers from the 9th grade of elementary school from two public schools in São Raimundo Nonato-PI. Therefore, we are guided by the theory of conceptual profiles that discuss the plurality of meanings that a given scientific concept can present, more specifically the concept of substance, since its understanding is very important for students' learning and for the understanding of others. chemical concepts. This research was carried out in two stages. In the first stage, a questionnaire was applied to trace the professional profile of teachers and map the main concepts used for the concept at hand. The second stage corresponded to the observation of three classes on the concept of substance and its applications taught by the research subjects, which were recorded with the aid of audiovisual equipment. Thus, the results showed a polysemy of concepts about substance, emerging in the speeches of the two investigated teachers and, thus, we found that they use in their answers various ways of thinking about this concept, whether a more formal language, a scientific one, or a way of think simpler, everyday language. With this, we realize that scientifically accepted concepts are not always used at school to introduce students to a certain scientific term, such as chemical substance, but it is noteworthy that every form of thought must be considered, as they contribute to the construction of new forms of meanings.
\end{abstract}

Keywords: Conceptual profile; Substance; Teachers; Science teaching. 


\begin{abstract}
Resumen
Este artículo tuvo como objetivo analizar las formas de pensar sobre el concepto de sustancia movilizadas en el discurso de dos profesores de ciencias del noveno grado de la escuela primaria de dos escuelas públicas de São Raimundo Nonato-PI. Por tanto, nos guiamos por la teoría de los perfiles conceptuales que discuten la pluralidad de significados que puede presentar un determinado concepto científico, más concretamente el concepto de sustancia, ya que su comprensión es muy importante para el aprendizaje de los estudiantes y para la comprensión de los demás conceptos. Esta investigación se llevó a cabo en dos etapas, en la primera etapa se aplicó un cuestionario para trazar el perfil profesional de los docentes y mapear los principales conceptos utilizados para el concepto que nos ocupa. La segunda etapa correspondió a la observación de tres clases sobre el concepto de sustancia y sus aplicaciones impartidas por los sujetos de investigación, las cuales fueron grabadas con la ayuda de equipos audiovisuales. Así, los resultados mostraron una polisemia de conceptos sobre sustancia, emergiendo en los discursos de los dos profesores investigados y, así, encontramos que utilizan en sus respuestas diversas formas de pensar sobre este concepto, ya sea un lenguaje más formal o científico, o una forma de pensar más simple, lenguaje cotidiano. Con esto, nos damos cuenta de que los conceptos científicamente aceptados no siempre se utilizan en la escuela para introducir a los estudiantes a un determinado término científico, como sustancia química, pero es de destacar que toda forma de pensamiento debe ser considerada, ya que contribuye a la construcción de nuevos conceptos.
\end{abstract}

Palabras clave: Perfil conceptual; Sustancia; Maestros; Ensenãnza de la ciencia.

\title{
1. Introdução
}

Atualmente, diferentes pesquisas (Silva \& Amaral, 2013, Mortimer \& El-Hani, 2014, Silva, 2017, Amaral, Silva, \& Sabino, 2018, Sabino \& Amaral, 2018, Diniz Júnior \& Amaral, 2019) vêm buscando modificar a forma como o ensino de Ciências é direcionado nas escolas. Uma vez que esse ensino vem transcorrendo de forma limitada, baseado apenas no modelo de ensino transmissão-recepção, no qual os estudantes não encontram sentidos para estudar variados conceitos em sala de aula.

Assim, o ensino de Ciências está sendo trabalhado, em diferentes casos, de forma ineficiente sem que os conhecimentos prévios dos alunos sejam considerados e nem reconhecidos como parte do processo de ensino, ou seja, sem a articulação dos diversos campos do saber científico e nem das distintas concepções. Esta forma de ensinar incomoda muitos educadores e pesquisadores da área de ensino, uma vez que ensinar Ciências de tal forma não contribui para a compreensão dos fenômenos científicos e nem da realidade, muito menos colabora para a construção de novos conceitos científicos no processo de aprendizagem (Diniz Júnior, 2016).

Diante disso, acreditamos que é preciso trabalhar Ciências nas instituições de ensino, por meio da interação das diversas áreas do conhecimento e da articulação das ideias prévias dos estudantes com os novos conceitos que são adquiridos no processo de ensino e aprendizagem, promovendo assim o saber científico direcionado para a compreensão do mundo, fazendo com que as pessoas construam conhecimentos com o uso da reflexão, fornecendo um ensino que seja relacionado ao contexto do aluno, para que dessa forma eles possam compreender e explicar situações durante e após o processo de ensino, e que não apenas reproduzam e memorizem informações.

Nessa perspectiva, o ensino de Ciências nas últimas décadas vem passando por transformações à medida que teorias recentes traçam novas estratégias que aprimorem e forneçam um ensino científico de qualidade para os estudantes (Mortimer \& El-Hani, 2014). Uma das evoluções que vem ocorrendo é sobre o processo de conceituação, na qual compreende que a construção de significados em sala de aula se dá por intermédio da interação de experiências vivenciadas no cotidiano concatenadas ao processo de ensino e aprendizagem, para que assim os conhecimentos científicos escolares e do cotidiano possam ser problematizados mutuamente em sala de aula. Diante dessa ótica de ensino, segundo Mortimer e El-Hani (2014) o processo de conceituação passa a ser dinâmico e que no decorrer desse processo poderá sofrer alterações e reformulações por parte dos indivíduos, uma vez que de acordo com as interações os sujeitos irão construindo suas concepções. Assim, a conceituação é compreendida como um processo não estático ou monótono, que pode passar por redefinições diante das dinâmicas entre os indivíduos.

Nesse pensamento, verificamos que os professores são os principais mediadores no processo de construção de conhecimentos. Outrossim, são os docentes que têm os primeiros contatos na instrução dos estudantes na compreensão de 
fenômenos e processos que ocorrem na natureza e ao seu redor, sobretudo os científicos (Diniz Júnior, Silva, \& Amaral, 2015). Nesse sentido, a fala do professor no processo de ensino e aprendizagem em sala de aula deve ser considerada como um dos processos importantes na formação dos estudantes, pois é no contexto da sala de aula que ensinamentos atrelados ao cotidiano são discutidos na tentativa de construir significados na vida dos estudantes.

Nessa perspectiva, a teoria dos perfis conceituais contribui para o entendimento do progresso conceitual em salas de aula de Ciências (Sepúlveda, Mortimer, \& El-Hani, 2007) e dessa forma possibilita ao professor estruturar conceitos conscientizando os discentes para a existência de modos de interpretação plural referente a determinado termo, orientando-os a utilizá-los em contextos e situações apropriados.

E de acordo com Mortimer e El-Hani (2014) a teoria dos perfis conceituais permite entender que os indivíduos têm distintas maneiras de perceber e representar o mundo, e que diferentes modos de pensar, formados ao longo de nossas experiências de vida e influenciados pelo o contexto histórico (Diniz Júnior \& Amaral, 2019), podem ser empregados a múltiplos contextos. Nesse sentido, os perfis conceituais devem ser concebidos como modelos da heterogeneidade de pensamentos usados pelos indivíduos para significar suas experiências.

E pensando na heterogeneidade de modos de pensar, segundo Silva e Amaral (2013) o conceito de substância é polissêmico e de grande relevância na aprendizagem conceitual em sala de aula, uma vez que, é muito utilizado em sala de aula e seu entendimento é muito importante para a aprendizagem de outros conceitos químicos. Além disso, compreendemos que este acompanha o discurso de professores e estudantes ao longo de suas vidas (Silva, 2011).

Por meio do perfil conceitual de substância (Silva \& Amaral, 2013), novas estratégias para o ensino de Ciências podem ser elaboradas como o uso de ideias sobre substância em diferentes contextos, além de possibilitar caminhos para uma consciência dos professores e estudantes acerca das distintas concepções que este conceito apresenta. Diante disso, temos como principal objetivo analisar modos de pensar o conceito de substância mobilizadas na fala de dois professores de Ciências do $9^{\circ}$ ano do Ensino Fundamental de duas escolas da rede pública de São Raimundo Nonato - PI.

\section{A teoria dos perfis conceituais}

Os primeiros estudos mencionando perfil conceitual foram instituídos em meados da década de noventa, quando Mortimer propôs a noção da teoria do perfil conceitual (Mortimer, 1995). Em trabalhos recentes a teoria passou por reformulações (Mortimer \& El-Hani, 2014). A mesma discute acerca da pluralidade de significados que um determinado conceito científico pode apresentar considerando compromissos epistemológicos ${ }^{1}$, ontológicos ${ }^{2} \mathrm{e}$ axiológicos ${ }^{3}$. Inicialmente, o modelo do perfil conceitual elaborado por Mortimer, era uma forma de refutar a ideia principal do modelo de mudança conceitual de Posner et al. (1982) de que os estudantes deveriam abandonar seu conhecimento prévio ao entrar em contato com o conhecimento científico (Mortimer, Scott, \& El-Hani, 2009).

Nesse sentido, este modelo defende que as concepções iniciais dos estudantes fazem parte do processo de ensino e devem ser relacionadas com os conceitos científicos, desenvolvendo o processo de construção de significados (Mortimer, 2000). Sendo assim, na sala de aula coexistem múltiplas interpretações sobre um conceito específico, e que essa multiplicidade de pontos de vista deve ser considerada, pois auxiliam na aprendizagem e evolução conceitual dos estudantes.

Para Mortimer e El-Hani (2014) os conceitos são construídos na interação do sujeito com o meio social que ele participa, e a partir daí o mesmo faz definições utilizando interpretações que dão sentido à sua experiência diária. E os

\footnotetext{
${ }^{1}$ Epistemológico: relativo à produção do conhecimento e as diferentes interpretações da natureza atrelados à filosofia;

${ }^{2}$ Ontológico: se refere à natureza do objeto (o que é o objeto);

${ }^{3}$ Axiológico: está relacionada com valores e finalidades atribuídos aos objetos.
} 
diferentes conceitos científicos podem ser classificados em duas categorias de pensamento, sendo a primeira de natureza informal (opiniões próprias do indivíduo adquiridas no cotidiano) e a segunda de natureza científica (construída no decorrer do processo de ensino e aprendizagem) (Mortimer, 2000).

Segundo Silva e Amaral (2016) a existência dos diferentes significados aplicados a um determinado conceito demonstra duas linguagens de discurso em que as concepções se constroem em realidades e contextos distintos, mas que no decorrer do processo de construção do conhecimento científico, se inter-relacionam, permitindo o surgimento de novos significados para a compreensão dos fenômenos científicos e da vida.

De acordo com Mortimer e El-Hani (2014) a teoria dos perfis conceituais permite estruturar a diversidade de modos de pensar um conceito e situar aquelas concepções informais que encontram sentido em contexto específico. Além disso, a teoria dos perfis conceituais (Mortimer \& El-Hani, 2014) traz várias contribuições à sala de aula, uma delas é ajudar entender o processo de construção de significados, e permite entender as diferentes aplicações que um conceito científico pode apresentar.

Segundo Mortimer (1997, p. 202) "uma única forma de pensamento é insuficiente para lidar com um único conceito". No entanto, na maioria das vezes quando nos referimos a definições conceituais, acreditamos que um determinado termo apresenta uma única interpretação, e por isso, o perfil conceitual ajuda entender o pluralismo de pensamentos acerca de conceitos científicos.

Ademais, conforme Araújo (2014), os estudos sobre perfis conceituais se mostram importantes para o ensino de Ciências, uma vez que subsidia a proposição da aplicação de um ensino dedicado a valorização das diversas visões atribuídas a um conceito. Desse modo, a autora defende que a teoria em discussão também colabora para o desenvolvimento de novas pesquisas científicas, porquanto, mediante a perspectiva de perfil conceitual, muitos outros perfis conceituais vêm sendo propostos, possibilitando assim, a evolução do conhecimento científico e a compreensão da heterogeneidade de significados que vários conceitos científicos apresentam.

\section{O perfil conceitual de substância}

A partir dessa perspectiva a respeito dos perfis conceituais, foi proposto por Silva (2011) e Silva e Amaral (2013), considerando a evolução conceitual para o conceito de substância ao longo da história das Ciências, o perfil conceitual de substância, sendo este um conceito polissêmico, apresentando diversas ideias distintas em relação à sua definição, uma vez que para a proposição de um perfil conceitual, um determinado termo precisa ser polissêmico. Isto quer dizer que um conceito tem que apresentar diferentes concepções.

De acordo com Silva (2011) para a formação de um perfil conceitual precisam ser estabelecidas zonas, (onde o autor considerou para a estruturação destas, compromissos epistemológicos e ontológicos) que representarão o caráter plural de um tema especifico a ser perfilado. Cada zona representa ainda uma característica própria do tipo de pensamento que está sendo utilizada na definição de um dado assunto cientifico.

Consoante Silva e Amaral (2013) o conceito de substância é de grande relevância nas aulas de Química, e ainda consideram que a estruturação dos vários significados atribuídos a ele, em termos de um perfil conceitual, pode contribuir para o avanço nos estudos sobre perfis conceituais, considerando esta como uma teoria que poderá suportar o processo de ensino e aprendizagem além de possibilitar a análise da evolução conceitual em sala de aula.

Silva e Amaral (2013) ainda acrescentam a isso, a possibilidade de situar as concepções informais dos alunos sobre substância em determinados contextos, possibilitando uma compreensão sobre a resistência que elas apresentam a mudanças e o desgaste de alguns modelos de ensino que tentaram promover uma substituição dessas concepções por novas ideias (científicas) no processo de ensino e aprendizagem. 
A partir da proposição do perfil conceitual de substância (Silva, 2011, Silva \& Amaral, 2013) cinco zonas conceituais foram determinadas. Todavia, em trabalhos atuais (Silva, 2017, Sabino \& Amaral, 2018) duas dessas zonas foram revisadas e modificadas, considerando compromissos presentes nas experiências dinâmicas de discurso e representatividade dos sujeitos na contemporaneidade. A redefinição para as zonas do perfil aqui discutido, ocorreu uma vez que em trabalhos iniciais que versam sobre este conceito, foram considerados apenas concepções egressas de compromissos epistemológicos e ontológicos, não obstante, nas pesquisas recentes de Sabino e Amaral (2018) são consideradas ideias advindas de dimensão axiológica. Desse modo, para o estudo das zonas dos perfis conceituais de substância são considerados três compromissos do conhecimento: epistemológicos, ontológicos e axiológicos.

Neste sentido, cada zona apresenta características que indicam os distintos modos de definir substância química, estruturadas a partir de diferentes compromissos epistemológicos, ontológicos e axiológicos.

As zonas de um perfil conceitual representam diferentes formas de ver e representar a realidade, trazem informações indicando não só a natureza e/ou o tipo de pensamento, mas também o contexto que se originou aquela ideia manifestada pelo sujeito. Assim, o contexto representa concepções que foram construídas em períodos históricos e contemporâneos.

Assim sendo, os diferentes compromissos epistemológicos, ontológicos e axiológicos contidos em cada uma delas, expressam informações que indicam determinadas características do contexto no qual o indivíduo participa, como a linguagem e a cultura, por exemplo. A partir dessas distintas interpretações, compreendemos que as zonas de um perfil conceitual são constituídas de informações que contêm a interação do indivíduo com o cotidiano, meio que se insere, e com o conhecimento científico escolar.

Em vista disso, Diniz Júnior e Amaral (2019) argumentam que as definições sobre substância representam concepções oriundas da filosofia clássica, da química moderna e aquelas que circulam em salas de aula de química, entre outras.

Desse modo, as cinco zonas propostas anteriormente por Silva e Amaral (2013) foram estabelecidas, a saber: zona generalista, zona essencialista, zona substancialista, zona racionalista e zona relacional, com a proposta de reformulação a zona essencialista passou a se denominar utilitarista/pragmática e a zona generalista foi ampliada. Perante isso, as zonas conceituais de substância elencadas segundo Silva (2017) passam a ser: zona generalista, utilitarista/pragmática, zona substancialista, zona racionalista e zona relacional. Cada zona é identificada num modo de pensar e forma de falar de acordo com as ideias expressas pelos os indivíduos e com a natureza (informal ou científica), assim a estruturação dessas ideias pode auxiliar para uma evolução conceitual em abordagens na sala de aula.

A zona generalista é aquela em que as ideias são reproduzidas do senso comum, em que "o termo substância é usado de forma intuitiva, generalizada, e qualquer objeto é classificado como substância” (Diniz Júnior, Silva, \& Amaral, 2015, p. 4). São expressas nessa zona concepções generalizadas e vagas a respeito da substância, não manifestando a preocupação em separar termos como mistura, substância, átomo e elemento químico. Logo, é comum nessa zona circular interpretações em que substância e mistura são um único constituinte, como por exemplo, considerar misturas como sal, água mineral, leite, como substância única. Além disto, esta zona passou por uma ampliação, e além dessa ótica, Sabino e Amaral (2018) incluíram ideias onde substância é classificada como essencial ou a essência dos materiais (visão antes considerada para a zona essencialista). Desse modo, as interpretações sobre substância são prévias e informais, adquiridas do cotidiano.

A zona essencialista foi redefinida por Silva (2017) passando a se denominar utilitarista/pragmática. Para as ideias pertencentes a essa zona, o autor elucida que a compreensão de substância é associada à aplicação ou utilidade que ela pode ter, principalmente para os seres humanos. Assim, substância é interpretada como sendo suas propriedades relevantes à manutenção da vida ou que tem utilidade prática possibilitando benefícios ou malefícios vitais. Desse modo, em alguns contextos as pessoas utilizam substâncias como sendo influenciadoras da manutenção da saúde, e por sua vez, que quando há a ingestão delas, algumas de suas propriedades são benéficas à saúde, ou em outras situações, maléficas. Um modo de pensar e 
forma de falar, associada a essa zona, é a justificativa para ingestão de determinados tipos de alimentos, que contêm nutrientes importantes para a saúde, porque tais alimentos são substâncias ou apresentam "substância" (ou "sustança", no sentido que são fortes e fornecem energia). Seguindo essa linha de pensamento, por meio da ingestão desses alimentos, as substâncias têm uma utilidade benéfica, pois fornecem mais energia ao organismo. Diante disso, a substância tem um valor prático, de utilidade à saúde do indivíduo, sendo esse tipo de interpretação corriqueira no dia a dia.

$\mathrm{Na}$ zona substancialista são considerados os compromissos na qual as propriedades da substância podem ser transferidas para seus constituintes (átomos e moléculas) (Diniz Júnior et al., 2015). Nesta zona, começam a emergir conceitos científicos sobre substancia química, contudo, há uma definição em que substância é o próprio material atribuindo a ela características como cor e cheiro, não fazendo distinção entre suas propriedades e seus constituintes. Assim sendo, essa zona apresenta a articulação de modos de pensar e formas de falar intuitivas com pensamentos científicos. Um exemplo é admitir que os átomos de ouro são amarelos, sem haver consciência de que essa característica é resultante de um de seus constituintes. Para Silva (2017) a linguagem substancialista está presente nas aulas de Química, nos livros didáticos, e muitas vezes pode causar confusões levando os químicos, sobretudo os estudantes, a cometerem erros, por isso a mesma se torna tão importante para a ciência (Mortimer, 1997 como citado em Silva, 2017, p.709), de maneira que a tomada de consciência para e existência dessas formas de conceituar o termo em discussão, possibilita que sejam aplicadas em contextos apropriados.

Já a zona racionalista, as concepções sobre substância têm caráter científico, segundo Silva e Amaral (2013) estão ideias que circulam no contexto do ensino de Química e que apresentam um nível mais elevado de reflexão em relação às zonas anteriores. O sujeito entende que substância apresenta determinadas propriedades que lhe são características (como por exemplo, ponto de fusão e ebulição da água) e sabe diferenciar termos como átomo, elemento químico, mistura, substância. Nesta zona também é considerada a visão microscópica e macroscópica de substância. Onde por meio da ótica microscópica se tem conhecimento das classificações das substâncias, como simples, compostas, orgânicas, e inorgânicas, que se definem a partir dos constituintes que as compõem. Logo, o sujeito compreende que atmosfera é formada por distintas substâncias. E na ótica macroscópica se pode identificar suas propriedades que as caracterizam e que se manifestam visivelmente, como por exemplo, as substâncias metálicas são determinadas por apresentarem brilho, maleabilidade, dureza. Por conseguinte, na zona racionalista estão expressões presentes no âmbito científico.

A zona relacional se caracteriza pela presença de interpretações mais reflexivas abstratas ou mesmo complexas para substância, onde esta precisa ser considerada além do mundo real e físico. Sendo assim, substância e suas características são determinadas a partir de trocas energéticas entre o ambiente e outras substâncias. Diniz Júnior, Silva e Amaral (2015) ratificam para o pensamento relacionista quando discorrem que o conceito de substância é compreendido levando em consideração as relações entre matéria e energia e como tal relação influencia nas propriedades e constituição das substâncias. Diante do exposto, não existem substâncias no mundo real e propriedades que reputamos serem precisas e exatas como substâncias 100\% puras ou a temperatura de ebulição da água ser $100^{\circ} \mathrm{C}$, esses padrões são uma aproximação teórica para elucidações no processo de ensino e aprendizagem. Destarte, a compreensão desta zona é de igual modo sobremaneira relevante para o planejamento no ensino em ciências, pois na maioria das vezes é pouco emergente em concepções a respeito de substância, indicando que os indivíduos não têm entendimento do jogo relacional entre substância, ambiente e energia.

As zonas discutidas acima revelam os variados modos de se conceituar substância química e os aspectos que concedem constatar a gênese dessas visões, assinalando, portanto, o caráter polissêmico deste tema. Ainda, as diferentes definições para o referido conceito, demonstram contextos em que as concepções são adquiridas e o perfil conceitual de substância é significativo para a compreensão da natureza, uma vez que substâncias estão presentes em nosso cotidiano.

Vale salientar, que não há expectativa de que diferentes modos de pensar e distintas formas de falar sejam substituídos por outros, ou que uma forma de compreender o conceito se sobreponha a outra, no entanto, que por meio da estruturação das 
distintas ideias seja dada a oportunidade de se perceber os diferentes significados atribuídos ao termo substância, em realidades diferentes (Diniz Júnior \& Amaral, 2019).

Em suma, as zonas generalista e essencialista são concepções adquiridas no cotidiano, que trazem informações da vivência cotidiana do sujeito e são reproduções de ideias que circulam no senso comum e que não apresentam caráter científico. A substancialista é a transição entre as ideias não científicas e científicas, e as zonas racionalista e relacional são concepções obtidas no processo de ensino e aprendizagem, conceitos de caráter científico.

\section{Metodologia}

Este trabalho trata-se de um estudo de natureza qualitativa, que segundo Gil (2008) se refere a interpretações feitas pelo pesquisador em relação ao objeto de estudo, não se preocupando com representatividade numérica, mas que prima pelo rigor a qualidade da pesquisa. O referente trabalho foi embasado nos estudos de Silva e Amaral (2013) e Silva (2017) sobre o perfil conceitual de substância, bem como na teoria dos perfis conceituais de Mortimer e El-Hani (2014).

Essa pesquisa foi realizada em duas escolas públicas da cidade de São Raimundo Nonato, interior do Piauí. Em cada uma das instituições, convidamos um professor que lecionava Ciências no $9^{\circ}$ ano, a escolha foi mediante a disponibilidade de participar do estudo. Para facilitar a identificação cada participante foi nominado de professor A e professor B, bem como suas respectivas escolas.

Na primeira etapa da pesquisa, aplicamos um questionário formado por treze questões com o objetivo de traçarmos o perfil profissional dos professores, assim como de mapear as principais concepções empregadas pelos os professores acerca do conceito de substância. Conforme ilustramos a seguir, sendo que as questões de 1 a 6 , foram direcionadas às concepções sobre substância, e as demais, relacionadas ao perfil profissional dos docentes.

Quadro 1: Perguntas do questionário.

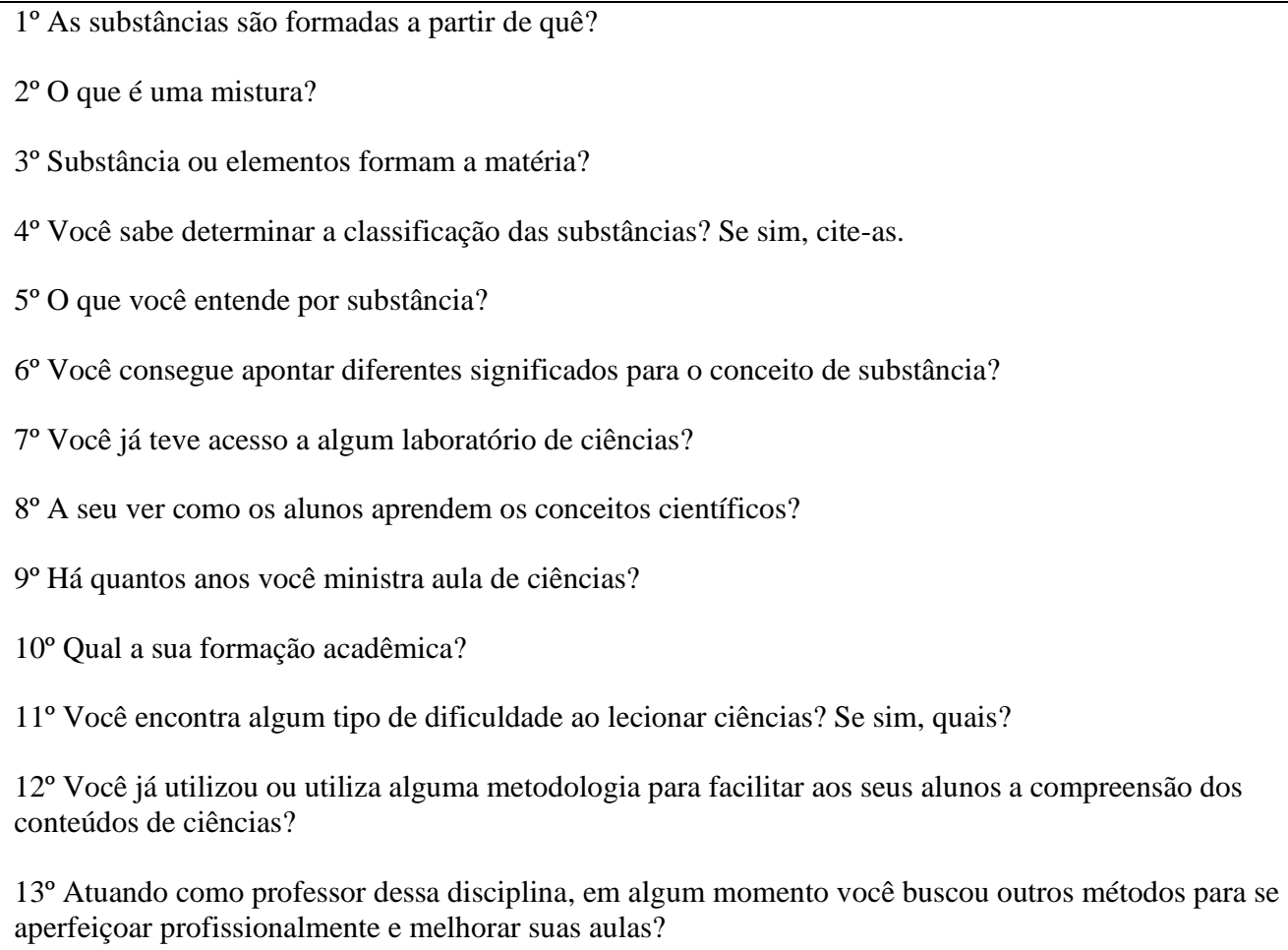

Fonte: Autores (2021). 
É importante ressaltar que o questionário teve 40 minutos de duração para cada professor e após respondido foi transcrito e analisado considerando categoricamente as respostas concedidas pelos sujeitos da pesquisa.

A segunda etapa correspondeu à observação das três aulas sobre o conceito de substância e suas aplicações ministradas pelos os sujeitos em investigação, foram registradas com o auxílio de equipamentos audiovisuais (câmera digital e celular). A filmagem teve por finalidade identificar quais zonas do perfil conceitual em estudo emergiam no discurso dos participantes em sala de aula. Foram filmadas duas aulas de 50 minutos com o professor A, e foi filmada uma aula de 50 minutos com o professor B. Salientamos que as aulas de ambos os professores não foram registradas sucessivamente, somente as aulas do professor A foram gravadas no mesmo dia. Também frisamos que para a divulgação dos dados obtidos nesta pesquisa, os professores assinaram um termo de compromisso. Após as filmagens, as aulas foram transcritas e analisadas segundos os critérios de análise estabelecidos.

Realizamos a análise dos dados seguindo os estudos da teoria dos perfis conceituais (Mortimer \& El-Hani, 2014) bem como os distintos modos de pensar e formas de falar do perfil conceitual de substância (Silva \& Amaral, 2013).

A análise do perfil do sujeito da pesquisa se deu mediante as respostas do questionário referentes ao perfil profissional dos professores. Pudemos verificar a formação acadêmica, o tempo de atuação no ensino de ciências, a metodologia utilizada para lecionar esta disciplina, se têm o acesso a laboratórios de ciências. Salientamos que analisamos as concepções dos professores utilizando as ideias sobre as cinco zonas do perfil conceitual de substância proposta por Silva e Amaral (2013) e aprimorado por Silva (2017).

Por meio das observações em sala de aula, buscamos identificar quais zonas predominavam no discurso dos professores. Para isto, utilizamos os critérios colocados por Silva (2017) para identificação das zonas durante o discurso dos professores. Esses critérios são baseados em cada modo de pensar e forma de falar que determinam as zonas conceituas do perfil em estudo. Diante do exposto, o quadro a seguir expõe as principais características que possibilitam identificar as zonas deste perfil.

Quadro 2: Principais características das zonas do Perfil conceitual de Substância.

\begin{tabular}{|l|l|}
\hline \multicolumn{1}{|c|}{ Zona } & \multicolumn{1}{c|}{ Características } \\
\hline Generalista & Substância é compreendida como qualquer material ou objeto \\
\hline Utilitarista/Pragmática & Substância compreendida pela sua utilidade nos materiais \\
\hline Substancialista & Substância é compreendida como a própria propriedade dos materiais \\
\hline Racionalista & $\begin{array}{l}\text { Substância compreendida por suas características, propriedades e constituição } \\
\text { atômico molecular }\end{array}$ \\
\hline Relacional & Substância é relacionada com energia e massa. \\
\hline
\end{tabular}

Fonte: Silva (2017).

\section{Resultados e Discussão}

Para a análise dos dados obtidos e identificação dos modos de pensar associados a formas de falar sobre o perfil conceitual de substância utilizamos os estudos de Silva e Amaral (2013) e Silva (2017), considerando as adequações realizadas em pesquisas recentes. 


\subsection{Análise do questionário}

Por meio do questionário que contemplou treze questões referentes ao conceito de substância química e ao perfil profissional dos dois docentes de duas escolas da rede pública da cidade de São Raimundo Nonato, interior do Piauí, sujeitos da pesquisa investigados, se obteve os resultados mediante as respostas de cada um.

O questionário buscou obter informações referentes ao perfil profissional dos dois docentes sujeitos da pesquisa e suas definições empregadas a respeito do conceito de substância, conforme demonstrado a seguir no quadro 3.

Quadro 3: Perfil profissional dos professores e definições empregadas para o conceito de substância.

\begin{tabular}{|c|c|c|}
\hline \multirow{2}{*}{ Perguntas } & \multicolumn{2}{|r|}{ Respostas } \\
\hline & Professor A & Professor B \\
\hline $\begin{array}{c}1^{\circ} \text { As substâncias são formadas a } \\
\text { Partir de quê? }\end{array}$ & $\begin{array}{l}\text { São formadas por } \\
\text { átomos de elementos } \\
\text { químicos em } \\
\text { proporções específicas. }\end{array}$ & $\begin{array}{l}\text { Os átomos se unem e formam moléculas, e essas } \\
\text { formam as substâncias. }\end{array}$ \\
\hline $2^{\circ} \mathrm{O}$ que é uma mistura? & $\begin{array}{l}\text { É a reunião de duas ou } \\
\text { mais substâncias puras. }\end{array}$ & Associação de duas ou mais substâncias. \\
\hline $\begin{array}{l}3^{\circ} \text { Substância ou elementos formam } \\
\text { a matéria? }\end{array}$ & $\begin{array}{l}\text { Sim, substância ou } \\
\text { elementos } \\
\text { formam uma porção de } \\
\text { matéria. }\end{array}$ & $\begin{array}{l}\text { Os elementos formam as substâncias, são } \\
\text { dotados de massa e ocupam lugar no } \\
\text { espaço, consequentemente são matéria. }\end{array}$ \\
\hline $\begin{array}{c}4^{\circ} \text { Você sabe determinar a classificação das } \\
\text { substâncias? Se } \\
\text { Sim, cite-as. }\end{array}$ & $\begin{array}{l}\text { Sim. Simples e } \\
\text { compostas. }\end{array}$ & $\begin{array}{l}\text { Simples: formadas por átomos do mesmo } \\
\text { elemento químico. Exemplo: } \mathrm{O}_{2} \mathrm{e} \mathrm{H}_{2} \text {. } \\
\text { Compostas: formadas por dois ou mais } \\
\text { elementos químicos. Exemplo: } \mathrm{H}_{2} \mathrm{O}, \mathrm{H}_{2} \mathrm{SO}_{4} \text {. }\end{array}$ \\
\hline $5^{\circ} \mathrm{O}$ que você entende por substância? & $\begin{array}{l}\text { É uma porção de } \\
\text { matéria que tem } \\
\text { propriedades bem } \\
\text { definidas. }\end{array}$ & Conjunto de moléculas iguais entre si. \\
\hline $\begin{array}{l}6^{\circ} \text { Você consegue apontar diferentes } \\
\text { Significados para o conceito de substância? }\end{array}$ & Não. & $\begin{array}{l}\text { Existe o conceito popular no sentido de ter } \\
\text { Disposição. Faço uma análise enfocando o } \\
\text { conceito real proposto pela Química. }\end{array}$ \\
\hline $\begin{array}{c}7^{\circ} \text { Você já teve acesso a algum laboratório de } \\
\text { ciências? }\end{array}$ & Sim. & $\begin{array}{l}\text { Sim. Muito raramente durante o meu curso. E, às } \\
\text { vezes, visitas aos laboratórios da UESPI e } \\
\text { UNIVASF. }\end{array}$ \\
\hline $\begin{array}{l}8^{\circ} \text { Ao seu ver como os alunos aprendem os } \\
\text { conceitos científicos? }\end{array}$ & $\begin{array}{l}\text { Através de } \\
\text { experimentos. }\end{array}$ & $\begin{array}{l}\text { Acredito que relacionando a sua vivência } \\
\text { com a compreensão do conhecimento } \\
\text { mediado pelo professor ou ao assistir } \\
\text { documentários, entrevistas, pesquisas. }\end{array}$ \\
\hline $\begin{array}{l}9^{\circ} \text { Ha quantos anos você ministra aula de } \\
\text { Ciências? }\end{array}$ & 7 anos. & A uns 12 anos. \\
\hline $10^{\circ}$ Qual a sua formação acadêmica? & $\begin{array}{c}\text { Graduação em Ciências } \\
\text { Biológicas. }\end{array}$ & Licenciatura Plena em Ciências Biológicas. \\
\hline $\begin{array}{l}11^{\circ} \text { Você encontra algum tipo de dificuldade } \\
\text { ao lecionar ciências? Se sim, quais? }\end{array}$ & Não. & $\begin{array}{c}\text { Sim. As formações, geralmente concentram } \\
\text { todas as disciplinas dentro do momento; } \\
\text { pouco acesso às novidades, principalmente, } \\
\text { parte prática; desde 2014, a quantidade de } \\
\text { livros didáticos é insuficiente para todos os } \\
\text { alunos; a necessidade de transportar material de sala } \\
\text { em sala, por inexistência de um local específico para } \\
\text { a prática. }\end{array}$ \\
\hline
\end{tabular}




\begin{tabular}{|c|c|c|}
\hline $\begin{array}{c}12^{\circ} \text { Você já utilizou ou utiliza alguma } \\
\text { metodologia para facilitar aos seus } \\
\text { Alunos a compreensão dos conteúdos de } \\
\text { ciências? }\end{array}$ & Sim. & $\begin{array}{c}\text { Sim. Procuro sempre utilizar na medida do } \\
\text { possível, materiais e experimentos que } \\
\text { possam facilitar a compreensão dos alunos. }\end{array}$ \\
\hline $\begin{array}{c}13^{\circ} \text { Atuando como professor dessa } \\
\text { disciplina, em algum momento você } \\
\text { buscou outros métodos para se aperfeiçoar } \\
\text { profissionalmente e } \\
\text { melhorar suas aulas? }\end{array}$ & Sim. & $\begin{array}{c}\text { Faço todos os cursos ofertados pelas } \\
\text { instituições a qual pertenço. Só que } \\
\text { dificilmente há algo específico e prático, } \\
\text { salvo exceções. }\end{array}$ \\
\hline
\end{tabular}

Fonte: Autores (2021).

Com relação às primeiras questões que buscavam mapear os modos de pensar dos professores sobre o conceito de substância (questões 1,2,3,4,5,6) identificamos diferentes modos de pensar e formas de falar o referido conceito, e foi caracterizado em zonas, demonstrando o caráter polissêmico do conceito de substância. Sobre as falas dos professores verificamos emergências expressivas alinhadas a visões científicas do conceito de substância. Algo que segundo Diniz Júnior et al. (2015) colocam que os professores ao responderem questões ligadas a sua prática utilizam de ideias científicas, uma vez que ocorre a predominância de definições advindas de livros didáticos e a conhecimentos de seus processos formativos.

Quando foi analisada a resposta dos dois professores para a primeira questão, Quadro 3, identificamos que suas definições abrangem a zona racionalista, pois o professor A tem consciência das propriedades que formam as substâncias e sabe distinguir átomos, substância e elemento químico. O professor B define substância a partir de sua composição (átomos, moléculas). Desse modo constatamos que ambos os docentes expressam características da natureza microscópica e submicroscópica das substâncias.

Em relação à segunda pergunta, Quadro 3, observamos que ambos os docentes trazem ideias racionalistas, na qual entendem que mistura é a junção de duas ou mais substâncias, e o que de fato aponta uma capacidade de empregar o conceito de substância e diferenças de conceitos próximos como o de mistura, que em muitos casos são confundidos e tratados como um único elemento. Vale destacar que o professor A, ao afirmar que seria a união de substâncias puras, ele expõe um pensamento generalista, uma vez que na natureza não existe substância com 100 \% de pureza.

Sobre a terceira pergunta, Quadro 3, quando se referem o que constitui a matéria, averiguamos também a emergência de zonas racionalistas/generalistas, todavia o professor A responde de uma maneira vazia, sem reflexão do que está interpretando, porém o professor B dá uma definição apresentando os elementos químicos como formadores de substâncias, contudo, ilustra que as substâncias são formadas por elementos, algo que destitui a ideia que as substâncias são formadas por moléculas e estas, por sua vez, por átomos que constituem numa visão macroscópica a constituição da matéria.

Já na quarta pergunta, Quadro 3, que tratava da classificação das substâncias observamos ideias racionalistas, na qual trataram substância a partir de suas especificações macro e microscópicas. Na exemplificação do professor B verificamos com mais plausibilidade o surgimento desse modo de pensar e forma de falar, quando ilustra $\mathrm{O}_{2}$ e $\mathrm{H}_{2}$ como substâncias simples, pois são formadas por átomos do mesmo tipo e substâncias compostas formadas por mais de dois átomos diferentes, por exemplo, $\mathrm{H}_{2} \mathrm{SO}_{4}$.

Na quinta pergunta, Quadro 3, que abordava a definição de substância, notamos que os professores apresentaram conceitos pertencentes à zona racionalista. O professor A define substância utilizando ideias propostas pela Química ao ter consciência das distintas propriedades que substância apresenta. O professor B define substância por meio da visão microscópica.

Na sexta pergunta, Quadro 3, não foi identificada nenhuma zona na resposta do professor A, pois o mesmo teve dificuldade de apresentar e problematizar a heterogeneidades de interpretações acerca do conceito de substância. Já o professor 
B tentou apresentar alguns exemplos, atribuídos à substância quando fala que promove a interação entre o conceito popular e o utilizado na Química. Porém, na sua resposta emergiu a zona utilitarista/pragmática. Este pensamento surge quando o referido professor aponta que substância é necessária à manutenção da vida e tem utilidade prática gerando benefício à vida quando faz uso do termo "disposição", corroborando assim, com a explanação de Silva (2017) quando elucida que nesta zona o sujeito utiliza esse tipo de pensamento ao compreender que a substância apresenta propriedades importantes que garantem a manutenção da vida e tem utilidade prática, podendo ainda garantir benefício ou malefício à vida.

Quanto às demais questões que se referem ao ensino de ciências e ao acesso a recursos que subsidiam a prática científica, como laboratório, sétima pergunta, Quadro 3, verificamos que os docentes em algum momento acessaram um laboratório, mas o professor B ressalta que raramente realizou visitas às instituições acadêmicas da cidade ou durante o período da formação inicial ou enquanto docente da educação básica.

Na questão oito, Quadro 3, os dois professores têm uma visão distinta para o aprendizado em ciências dos estudantes. Enquanto o professor A diz que eles aprendem por intermédio da experimentação prática, o professor B compreende que seus alunos aprendem no dia a dia atrelado com a intervenção do que o educador ensina, e por meio de materiais referentes ao tema científico.

$\mathrm{Na}$ resposta do professor em questão pudemos verificar um ensino em que ocorre a interação das experiências cotidianas e escolar, sendo o professor o mediador de tal interação, e isto é um dos elementos que promove um ensino de ciências contextualizado, relacionando os conceitos da sala de aula com o que os estudantes vivenciam fora da escola (Maldaner \& Zanon, 2010).

No entanto, conforme observamos na nona pergunta, Quadro 3, o professor A e o docente B, têm 7 e 12 anos, respectivamente, que lecionam Ciências no Ensino Fundamental o que segundo Maldaner e Zanon (2010) os conhecimentos do professor não constituem apenas na formação inicial, mas mediante suas interações e experiências.

Segundo o que podemos observar na décima pergunta, no Quadro 3, ambos os professores têm formação em Ciências Biológicas. Por meio das anotações feitas durante a pesquisa, constatamos que o professor A possui pós-graduação em Gestão Ambiental, o que aponta que os conhecimentos são alinhados à área de Biologia, algo que pode trazer problemáticas no processo de formação conceitual dos estudantes, tendo em vista que a Ciências do $9^{\circ}$ ano do Ensino Fundamental trata de conhecimentos químicos e físicos.

Observamos também na décima primeira pergunta, Quadro 3, quando referido sobre as dificuldades encontradas pelos educadores ao ensinar ciências, o mesmo destaca a ausência de laboratório, o que dificulta de fato, a realização de atividades experimentais. Algo que chamou atenção foi a resposta do professor A, afirmando que não tem dificuldades para ensinar ciências, porém não justificou os motivos.

E na questão doze, Quadro 3, conferimos que tanto o professor A quanto o professor B buscam maneiras para promover aos seus estudantes uma melhor compreensão de ciências, porém não elencaram exemplos no intuito de complementarem suas falas. Isso aponta elementos da dificuldade de muitos professores de problematizarem e refletirem sobre sua própria prática (Maldaner \& Zanon, 2010).

Em relação à décima terceira pergunta, Quadro 3, que tratou do aperfeiçoamento profissional dos docentes, o professor A diz que busca se aperfeiçoar profissionalmente, no entanto não especifica como. Já o professor B é mais explícito e aponta que faz vários cursos quando lhe são ofertados, mas raramente são cursos que dão uma formação específica. Sendo assim, verificamos que as formações/capacitações ofertadas para este docente não trata especificamente da aprendizagem em Educação em Ciências, mas temas gerais, que geralmente reúne todos os docentes das escolas e participam de palestras para todo o corpo docente, sem levar em consideração as variadas áreas de atuação. 


\subsection{Análise da observação das aulas}

\subsubsection{Observação da aula do Professor A}

Por meio das observações em sala de aula, buscamos identificar quais zonas predominavam no discurso dos professores, utilizando os critérios, já discutidos no início deste trabalho, para identificação das zonas durante o discurso dos professores.

As observações das aulas como já elucidamos na metodologia, se deu por intermédio de filmagens de três aulas de Ciências abordando o conceito de substância. A seguir são ilustrados trechos das falas de cada professor, em que é observado em ordem alfabética cada trecho de discurso. Sendo assim, primeiro serão ilustrados extratos da fala do professor A e posteriormente extratos do discurso do professor B. Em alguns dos trechos expomos diálogo entre professor e aluno e vale ressaltar que os nomes dos estudantes são nomes fictícios, mantendo a identidade preservada, assim como dos docentes.

Quadro 4: Trechos da fala do professor A.

\begin{tabular}{|l|c|}
\hline \multicolumn{1}{|c|}{ Exemplos das falas } & Zonas identificadas \\
\hline $\begin{array}{l}\text { 1. Ficou claro aí a diferença? E o conceito de substância? E o conceito de substância? Vamos analisar. Se eu pegar, } \\
\text { se eu pegar bem aqui é. se eu pegar sal, sal e água e misturar? Sal e água, colocar junto. Eu tenho quantas } \\
\text { substâncias? }\end{array}$ & GENERALISTA \\
\hline $\begin{array}{l}\text { 2.O soluto. A água, o sal será dissolvido pelo? O sal será dissolvido pelo? Solvente que é a? a água. Beleza? Se eu } \\
\text { juntar, seu eu juntar água e açúcar? Eu vou obter uma solução? }\end{array}$ & RACIONALISTA \\
\hline $\begin{array}{l}\text { 3. Professor: Ferro. Pode ser ferro? ferro é um metal, né? Um elemento químico. } \\
\text { Beto: Então o ouro também é. }\end{array}$ & SUBSTANCIALISTA \\
$\begin{array}{l}\text { Professor: Formado por átomos de ferro, certo? } \\
\text { Beto: Ei, professor! } \\
\text { Professor: Portanto, somente por átomos de ferro. Portanto, ele é uma substância... } \\
\text { Beto: Ei, professor, então o ouro também é. } \\
\begin{array}{l}\text { Professor: Hã? O ouro? Sim. (Inaudível) } \\
\text { Beto: (Inaudível) }\end{array}\end{array}$ \\
\hline $\begin{array}{l}\text { 4. É uma porção, tá? É uma porção, é uma porção de matéria que tem propriedades bem definidas que estão... } \\
\text { então, uma substância, pessoal, nada mais é do que uma porção aí da matéria que tem propriedades aí bem } \\
\text { definidas, certo? Por exemplo, por exemplo aqui. Vamos pegar um exemplo aqui, exemplos aqui, dá alguns } \\
\text { exemplos. Um exemplo aí bem simples. Vamos pegar aí o.. a água , por exemplo, água. Água. A água, pessoal... } \\
\text { Quais são essas características que faz [sic] com que eu considero [sic] a água uma substância? Veja só! Primeira } \\
\text { coisa, a água ela é formada por átomos, tá? Por átomos de hidrogênio e oxigênio, não é isso? Ela é água.... }\end{array}$ & RACIONALISTA \\
\hline
\end{tabular}

Fonte: Autores (2021).

Conforme podemos observar no Quadro 4, o professor A apresentou diferentes modos de pensar e formas de falar sobre o conceito de substância, evidenciando a heterogeneidade de modos de pensar no discurso dele. Deste modo, durante sua fala emergiram diferentes zonas o que permitiu compreender o caráter polissêmico do conceito.

A zona racionalista, observada nos exemplos 2 e 4 do Quadro 4, apontaram ideias aceitas no âmbito científico, que são adquiridas por meio do processo de ensino e aprendizagem, como no contexto escolar, por exemplo. Esta zona foi a que mais surgiu durante as aulas do professor quando este abordava o tema substância em sala de aula. Segundo Diniz Júnior (2014), isso é algo bem característico na fala de professores, uma vez que envolvem conhecimentos relacionados ao processo formativo.

Nesse sentido, neste modo de pensar são empregados conceitos que se considera a visão macroscópica e microscópica de substância, compreendendo assim, que a mesma tem as propriedades definidas, conceitos que versam a distinção entre átomos, moléculas e substância. O professor A ao definir substância compreende que ela apresenta propriedades bem definidas, porém não fez abordagens mais específicas como apontar quais são as características que a água, exemplo de 
substância citado no trecho referente a esta zona, apresenta, como sua polaridade, ponto de fusão e que ela é um solvente. Logo, compreendemos que ele utiliza os conceitos abordados nos livros didáticos, porquanto eles geralmente empregam conceitos rápidos, sem maiores aprofundamentos sobre o tema, corroborando aos estudos de Diniz Júnior (2014; 2016) e Diniz Júnior et al. (2015).

Apesar da zona racionalista ter sido predominante na fala do professor, também se observa a emergência de modos de pensar e formas de falar atrelados a zona generalista. Nesta zona as ideias do professor incorporam visões ingênuas sobre substância, em que se considera que qualquer coisa ou material é uma substância, não havendo o discernimento sobre a existência de várias substâncias e que as mesmas podem constituir um mesmo material (Silva \& Amaral, 2013). Não há distinção entre elemento, mistura e substância, há um uso não muito eficiente de que tudo é uma coisa só, ou seja, uma substância. E é exatamente isso que foi identificado no trecho 1, Quadro 4, quando o professor confunde mistura com substância. Para ele, ao juntar sal e água se obterá uma substância, o que na verdade implicará na formação de uma mistura. Ainda que seu discurso tenha prevalecido ideias cientificamente e quimicamente aceitas, vez ou outra ele expressa ideias intuitivas e ingênuas, geralmente compartilhadas entre as pessoas no contexto do dia a dia, pois normalmente as pessoas consideram misturas como sendo substâncias.

A zona pouco identificada na fala do professor foi a substancialista, trecho de fala 3, Quadro 4, nela ocorre a transição do pensamento intuitivo para o científico. Nesta zona há uma certa racionalidade sobre substância, já que há conceitos aceitos pela Química. A substância não apresenta determinadas características, mas é a própria propriedade da matéria (Silva \& Amaral, 2013). Verificamos que no diálogo do professor com o aluno Beto, ambos substancializam a propriedade metal. Apesar do ferro e ouro pertencerem ao grupo dos metais, na fala do professor percebemos que ele generaliza a propriedade metal, pois todo material que for semelhante ao ferro será um metal.

Mediante a análise dos trechos do professor A, verificamos que nem sempre na escola são apresentadas concepções cientificamente aceitas, que há uma considerável polissemia de conceitos, nos quais distintos modos de pensar e formas de falar são utilizados. Isto só vem a reforçar mais ainda existência do pensamento plural de um único indivíduo em que ele atribui uma diversidade de conceitos para substância. 


\subsubsection{Observação da aula do Professor B}

Quadro 5: Trechos da fala do professor B.

\begin{tabular}{|c|c|}
\hline Exemplos das falas & Zonas identificadas \\
\hline $\begin{array}{l}\text { 1.Vocês já ouviram falar é de alguém que estava se sentindo fraco, que teve que oh o médico disse: ô } \\
\text { fulano precisa se alimentar melhor para ter mais sustância, né? As vezes lembra um pouquinho, né? } \\
\text { Essa essa... essa situação lembra um pouco essa questão do conceito de substância. Mas o que que a } \\
\text { pessoa, né, popularmente ela quer dizer? Que essa pessoa ela precisa, né, de alguns tipos de nutrientes, } \\
\text { não é? Pra [sic] poder equilibrar seu organismo e ter essa energia é... necessária para desenvolver suas } \\
\text { atividades. Vocês já ouviram falar esse tipo de relação nesse aspecto? Quem já ouviu falar levanta a } \\
\text { mão pra [sic] vê [sic] se fica mais fácil. Estão com vergonha. }\end{array}$ & UTILITARISTA/PRAGMÁTICA \\
\hline $\begin{array}{l}\text { 2. Não. Elas vão ter formatos e você vai encaixando e você pode até formar novos brinquedos a partir } \\
\text { daquilo ali, não é isso? Então, o trabalho que o químico faz é pegar, né? É o que a gente chama de } \\
\text { substância ou de matéria que existe e desmontar. Digamos que desse brinquedo de montar é. foi } \\
\text { montando um carrinho, nessas, através dessas pecinhas foi montado um carrinho, certo? Então, a } \\
\text { criança, digamos, recebeu ali esse carrinho. O que que ela faz? Ela fica curiosa e ela desmonta tudinho, } \\
\text { né? Pra [sic] entender como aquele processo foi feito. } \\
\text { Então, o químico ele faz isso também, né? ele estuda a matéria e tenta desvendar ali, né? A seu... a sua } \\
\text { composição. }\end{array}$ & GENERALISTA \\
\hline $\begin{array}{l}\text { 3. Professor: Os átomos, tá [sic] bom? Então, para.... prestando atenção aqui e percebendo se vocês } \\
\text { realmente entenderam. } \\
\text {-Joaquim, eu vou fazer o seguinte: a Izabella vai vir aqui primeiro, vem cá Izabella! Inaudível. Não tem } \\
\text { problema não. Vocês não vão vir não. Ó, nós temos aqui dois diagramas. Estão vendo? Diagramas são } \\
\text { essas representações aqui, ó. Nós temos o diagrama A e o diagrama B. Embaixo tem uma legenda. O } \\
\text { vermelho simboliza qual átomo? } \\
\text { Vários alunos: Hidrogênio. } \\
\text { Professor: O hidrogênio tem o símbolo H. O azul que tem o símbolo? } \\
\text { Vários alunos: inaudível. } \\
\text { Professor: e o preto é o carbono que tem o símbolo C. Então, a Izabella vai me dizer o seguinte, ó, } \\
\text { presta atenção! Izabella, quantos átomos têm aqui nesse diagrama A? }\end{array}$ & SUBSTANCIALISTA \\
\hline $\begin{array}{l}\text { 4. De substância. Então, o que que eu posso definir como substância química? Que é o conjunto de } \\
\text { moléculas iguais entre si. Então, todas as moléculas de } \mathrm{H}_{2} \mathrm{O} \text {, né? eu vou chamar de quê quando elas } \\
\text { estão, né? estão é. Juntinhas elas formam o que a gente chama de quê? De Substância química. Quando } \\
\text { eu vou estudar essa, essa parte aqui, uma parte isolada, né, digamos individualmente a molécula é. essa, } \\
\text { essa fórmula aqui que eu tenho } \mathrm{H}_{2} \mathrm{O} \text {, eu digo que é o quê? Uma molécula. Tá [sic] bom? }\end{array}$ & RACIONALISTA \\
\hline
\end{tabular}

Fonte: Autores (2021).

De acordo com os dados expostos no Quadro 5, identificamos diferentes modos de pensar e formas de falar na fala do professor B. Assim como no discurso do professor A, a zona mais predominante na fala do professor B é a racionalista. As zonas que emergem com menor frequência são a generalista, utilitarista/pragmática e substancialista. Esta última é a menos usada em suas falas. Não identificamos a zona relacional durante as aulas.

A zona racionalista é a que mais emerge na fala do professor. No trecho 4, Quadro 5, conseguimos identificar uma ideia racionalista quando o professor conceitua substância a partir da união de moléculas. Na sua visão, distingue moléculas e substâncias, considerando que quando várias moléculas se juntam formam uma substância. Sendo assim, seu pensamento caracteriza uma concepção cientificamente correta.

A interpretação utilitarista/pragmática é baseada na ideia de que a substância tem utilidade de manutenção da vida, propiciando benefícios e malefícios aos seres humanos. Na fala do professor referente a essa zona, trecho 1, Quadro 5, ele utiliza uma ideia do impacto benéfico que o uso da substância causará no organismo. Segundo seu ponto de vista, a substância tem a capacidade de fornecer disposição ao organismo quando se consome alguns tipos de alimentos que tem em sua 
composição substâncias. Sendo assim, a substância resultará no aumento de energia do organismo, pois quando a pessoa está fraca tem que ingerir alimentos ricos em algumas substâncias, portanto, é o caráter útil a respeito de substância da fala do professor.

O professor no trecho 2, Quadro 5, exibe um conceito generalista quando usa uma visão macroscópica de substância e que a mesma é qualquer matéria. "Então, o trabalho do químico faz é pegar, né?" Essa parte do trecho indica uma visão macroscópica, em que substância é algo concreto (real) e que se pode tocar. No final da frase quando diz: "É o que a gente chama de substância ou de matéria”, ele considera que qualquer matéria é uma substância. Então na zona generalista, as substâncias são consideradas numa ótica macroscópica e concreta, sendo definidas de forma ingênua, onde qualquer coisa ou objeto é uma substância (Silva \& Amaral, 2013).

O caráter substancialista verificado no trecho 3 , Quadro 5 , surge na fala do professor quando utiliza as simbologias para indicar os átomos de hidrogênio e de carbono. Ao utilizar a simbologia $\mathrm{H}$ e C para os átomos de hidrogênio e de carbono, o professor em questão utiliza as letras que representam cada átomo (neste caso representação de elemento da tabela periódica) como se fossem a característica que define o que é um hidrogênio e um carbono.

Pelo o exposto, por meio dos dados analisados, notamos nos discursos a predominância de ideias racionalistas, cientificamente aceitas, mas essa assiduidade de pontos de vista 'quimicamente corretos' não impediu o surgimento de zonas que caracterizam visões informais, que talvez foram adquiridos numa situação cotidiana de cada professor. Desse modo, surge o caráter polissêmico nas falas dos professores, onde diferentes formas de raciocínio e cada zona emergente corresponde a distintos modos de pensar e conceituar substância por cada um dos professores.

Perante isso, é necessário utilizar estudos relacionados a observação da fala de professores no processo de ensino e aprendizagem, incluindo a teoria dos perfis conceituais (Motimer \& El-Hani, 2014), para se identificar quais conceitos os professores empregam nesse processo e se eles têm consciência dos diversos modos de pensar e formas de falar que utilizam ao definir um determinado conceito. Uma vez que essas pesquisas apontam para a polissemia de conceitos, elas são importantes para a construção de novos significados, porque o indivíduo já apresenta as ideias prévias e no processo de ensino adquire e/ou aprimora novas concepções. Outrossim são relevantes porque ressaltam para a valorização de cada modo de pensar, defendendo que distintas formas de interpretação devem ser consideradas no processo de ensino e aprendizagem e colaboram para que os docentes tenham consciência da pluralidade de concepções que utilizam, passando a organizá-las e utilizá-las em contextos adequados podendo, dessa forma, auxiliar seus alunos a igualmente aplicar cada ideia num contexto específico. Diante da observação do discurso dos professores, podemos, portanto, compreender o que eles estão transmitindo a seus alunos, e isso colabora para um ensino mais organizado e planejado.

\section{Considerações Finais}

A partir desse estudo, analisamos modos de pensar o conceito de substância mobilizadas na fala de dois professores de Ciências do $9^{\circ}$ ano do Ensino Fundamental de duas escolas da rede pública de São Raimundo Nonato-PI. E por meio da análise, onde utilizamos os dados do questionário, da observação e filmagem das três aulas de Ciências sobre o conceito de substância, verificamos o discurso plural dos professores sobre o conceito estudado em que expressaram os variados modos de pensar e falar esse conceito alinhados a visões cientificas e não-cientificas.

$\mathrm{Na}$ segunda fase, observação e filmagem das aulas, percebemos com mais clareza os distintos modos de pensar e formas de falar heterogêneos dos professores sendo emergentes as zonas do perfil conceitual de substância. Diante disso, tanto nas repostas ao questionário quanto nas aulas são apresentadas distintas formas de definir substância. 
Desse modo, ao analisarmos todos os dados obtidos entre as duas fases, conferimos que o discurso dos professores se aproximam à visão cientifica, porquanto a zona racionalista predominou em ambas as fases da pesquisa relacionadas às convicções sobre o termo abordado.

Ao analisarmos todos os dados, verificamos a predominância de um discurso racionalista, em que são utilizados pelos professores conceitos quimicamente e cientificamente aceitos. E além do discurso racionalista, os professores empregaram outras formas de reflexão, mas que apareceram com menos assiduidade.

Assim sendo, nossos resultados apontaram uma polissemia de conceitos sobre substância, emergindo nos discursos dos professores investigados e, assim, constatamos que utilizam em suas falas vários modos de pensar e formas de falar esse conceito, seja uma linguagem mais formal, a científica, ou uma maneira de pensar mais simples, a linguagem cotidiana. Com isso percebemos que nem sempre na escola são empregados conceitos aceitos cientificamente para se apresentar aos alunos um determinado termo científico, como é o caso de substância química, mas ressaltamos que toda forma de pensamento deve ser considerada, porquanto contribuem para a construção de novas formas de significados. No entanto, é necessário que saibamos utilizá-la nos contextos apropriados.

Nossos resultados apontaram ainda, que embora utilizem um discurso heterogêneo em suas explanações, valorizando assim as variadas formas de conceituar substância, os professores não demonstram ter consciência dessa heterogeneidade e tampouco de aplicá-la em contextos apropriados.

Pelo o exposto, a partir do uso do perfil conceitual de substância neste trabalho, constatamos que as pessoas fazem uso dos perfis conceituais durante as definições sobre um determinado tema, tendo consciência ou não disso.

Nessa perspectiva, os professores utilizam diversos modos de conceituar um determinado termo científico em sala e, diante disso, os perfis conceituais tornam-se uma ferramenta a ser utilizada por eles para que promovam um ensino planejado e contextualizado, uma vez que o professor ao utilizar esse modelo passa a ter consciência da existência dos distintos significados que ele atribui no dia a dia a um conceito visto na sala de aula. Assim, os professores mediarão o conhecimento com a valorização das diferentes visões do mundo, sendo cada uma delas utilizada nos contextos adequados por cada indivíduo.

Assim, defendemos o uso dos perfis conceituais, para que os professores se tornem conscientes do pluralismo de ideias que um conceito possui, porque são eles importantes no processo de construção de significados, para que assim promovam um ensino contextualizado, em que as ideias devem ser aplicadas em contexto que dão sentidos a elas. Outrossim, o uso dos perfis conceituais contribui para um ensino em ciências de qualidade, no qual podemos verificar os diferentes modos de pensar que os professores utilizam para ensinar um termo científico, com isso podemos averiguar se eles ensinam ciências com o uso de conceitos adequados e corretos a essa área.

Por conseguinte, a partir das discussões aqui apresentadas, pretendemos dar continuidade à nossa pesquisa envolvendo o uso dos perfis conceituais na compreensão, planejamento e contextualização do ensino de ciências.

\section{Referências}

Amaral, E. M. R., Silva, J. R. R. T., \& Sabino, J. D. (2018). Analysing processes of conceptualization for students in lessons on substance from the emergence of conceptual profile zones. Chemistry Education Research and Practice. 1010-1018. https://www.researchgate.net/publication/324994974_Analysing_processes_of_conceptualization_for_students_in_lessons_on_substance_from_the_emergenc e_of_conceptual_profile_zones

Araújo, A.O. (2014). O Perfil Conceitual de Calor e sua Utilização por Comunidades Situadas. 223 f. Tese (doutorado em educação e ciências) - Programa de Pós-graduação em Educação, Universidade Federal de Minas Gerais, Belo Horizonte, Minas Gerais, Brasil. https://repositorio.ufmg.br/bitstream/1843/BUOS-9JHKBE/1/tese_ang_lica_ara_jo.pdf

Diniz Jr., A. I. (2014). Análise de zonas do perfil conceitual de calor e substância em professores de Química da rede pública de Serra Talhada. Monografia (Graduação Licenciatura Plena em Química) - Universidade Federal Rural de Pernambuco/ Unidade Acadêmica de Serra Talhada, Serra Talhada, Pernambuco, Brasil. 
Diniz Jr., A. I. (2016). Análise de Zonas do Perfil Conceitual de Substância que Emergem na fala de uma Professora de Química da rede privada do Recife. Dissertação (Mestrado em Ensino de Ciências). Departamento de Educação, Universidade Federal Rural de Pernambuco, Recife, Pernambuco, Brasil.

Diniz Jr., A. I., Silva, J. R. R. T., \& Amaral, E. M. R. (2015). Relação entre Contextos e zonas do Perfil Conceitual de Substância na fala de professores de Química In. X Encontro Nacional de Pesquisa em Educação em Ciências- X ENPEC Águas de Lindóia, SP- 24 a 27 de novembro. http://www.abrapecnet.org.br/enpec/X-enpec/anais2015/resumos/R0328-1.PDF

Diniz Jr., A. I. \& Amaral, E. M. R. (2019). A Heterogeneidade do Discurso Docente: falando sobre substâncias a partir de diferentes situações. Revista Debates em Ensino de Química, 5,42-54. http://www.journals.ufrpe.br/index.php/REDEQUIM/article/view/2438/482483192

Gil, A.C. (2008). Métodos e Técnicas de Pesquisa Social. (6a ed.), Atlas.

Maldaner, O. A., \& Zanon, L. B. (2010). Pesquisa educacional e produção de conhecimento do professor de Química. In: SANTOS, W. L. P.; MALDANER, O. A. Ensino de Química em Foco. Ijuí: Ed. Unijuí.

Mortimer, E. F. (1995). Conceptual Change or Conceptual Profile Change? Science \& Education. Netherlands: Kluwer Academic Publishers, $268-283$.

Mortimer, E. F. (1997). Para Além Das Fronteiras da Química: relações entre filosofia, psicologia e Ensino de Química. Química Nova. $200-207$.

Mortimer, E. F. (2000). Linguagem e formação de conceitos no ensino de ciências. Belo Horizonte: Ed. UFMG, 382.

Mortimer, E. F., Scott, P., \& El-Hani, C. N. (2009). Bases teóricas e epistemológicas da abordagem dos perfis conceituais. In Anais do VII ENPEC, Florianópolis.

Mortimer, E. F., \& El-Hani, C. N. (2014). Conceptual Profiles: A Theory of Teaching and Learning Scientific Concepts. New York: Springer.

Posner, G. J., Strike, K. A., Hewson, P. W., \& Gertzog, W. A. (1982) Accommodation of a scientific conception: towards a theory of conceptual change. Science Education, 66, 211-227.

Sabino, J. D., \& Amaral, E. M. R. (2018). Utilização do perfil conceitual de substância no planejamento do ensino e na análise do processo de aprendizagem. Investigações em Ensino de Ciências, 23, 245-265. https://www.if.ufrgs.br/cref/ojs/index.php/ienci/article/view/923

Silva, J. R. R. T. (2011). Um perfil conceitual para o conceito de substância. 183. Dissertação (Mestrado em Ensino de Ciências). Departamento de Educação, Universidade Federal Rural de Pernambuco, Recife, Pernambuco, Brasil.

Silva, J. R. R. T. (2017). Diversos modos de pensar o conceito de substância química na história da ciência e sua visão relacional. Ciência e Educação, 707722.https://www.researchgate.net/publication/320342236_Diversos_modos_de_pensar_o_conceito_de_substancia_quimica_na_historia_da_ciencia_e_sua_vis ao_relacional

Silva, J. R. R. T., \& Amaral, E. M. R. (2013). Proposta de um Perfil Conceitual para Substância. Revista Brasileira de Pesquisa em Educação em Ciências, v. 13. n. 3 p. 53-72. https://periodicos.ufmg.br/index.php/rbpec/article/view/4271/2836

Silva, J. R. R. T., \& Amaral, E. M. R. (2016). Concepções Sobre Substância: relações entre contextos de origem e possíveis atribuições de sentidos. Química Nova na Escola. São Paulo, 38 (1), 70-78. http://qnesc.sbq.org.br/online/qnesc38_1/12-AF-3-15.pdf

Sepúlveda, C., Mortimer, E. F., \& El-Hani, C. N. (2007). Construção de um perfil para o conceito de adaptação evolutiva. In: Anais do VI ENPEC-Encontro Nacional de Pesquisa em Educação em Ciências. Florianópolis- SC. http://abrapecnet.org.br/atas_enpec/vienpec/CR2/p862.pdf 